Bulletin d'Histoire Contemporaine de

I'Espagne

$54 \mid 2020$

Les espaces du politique dans l'Espagne du Trienio liberal (1820-1823)

\title{
La idea de nación en el pensamiento y la acción política de José Ortega y Gasset
}

Juan BAGUR TALTAVULL

(2) OpenEdition

Journals

Edición electrónica

URL: http://journals.openedition.org/bhce/3107

DOI: 10.4000/bhce.3107

ISSN: 1968-3723

Editor

Presses Universitaires de Provence

Edición impresa

Fecha de publicación: 1 enero 2020

ISSN: 0987-4135

Referencia electrónica

Juan BAGUR TALTAVULL, « La idea de nación en el pensamiento y la acción política de José Ortega y Gasset », Bulletin d'Histoire Contemporaine de l'Espagne [En línea], 54 | 2020, Publicado el 01 julio 2020, consultado el 31 diciembre 2020. URL : http://journals.openedition.org/bhce/3107 ; DOI : https:// doi.org/10.4000/bhce.3107

Este documento fue generado automáticamente el 31 diciembre 2020.

Bulletin d'histoire contemporaine de l'Espagne 


\title{
La idea de nación en el pensamiento y la acción política de José Ortega y Gasset
}

\author{
Juan BAGUR TALTAVULL
}

\section{NOTA DEL EDITOR}

Tesis leída el 5 de noviembre de 2018 en la Universidad Complutense de Madrid.

Directores, prof. Juan Pablo Fusi y Antonio López Vega. Tribunal : profs: Elena

Hernández Sandoica (presidenta), Paul Aubert, Javier Zamora Bonilla, Isabel Ferreiro, Juan Lasaga.

1 La tesis estudia la idea de nación de José Ortega y Gasset, centrándose tanto en su dimensión teórica, como en la puesta en práctica en el foro público. Parte de la historia intelectual contextualista y de las tesis sobre la nacionalización centradas en el sujeto, tratando de responder a tres cuestiones: el motivo que tuvo para buscar una definición de la nación, la adscripción de su teoría a la idea de Kulturnation o a la de Staatsnation, y la existencia o no de fases en sus respuestas. Para ello, se plantea como hipótesis que Ortega configuró su idea de nación para resolver su crisis existencial, respondiendo a la realidad que le rodeaba a partir de la aplicación de la filosofía, y proponiendo como respuesta una actuación nacionalizadora que hizo de la intelectualidad su base.

2 Las fuentes esenciales han sido las Obras Completas, analizadas en su conjunto y no únicamente en los textos que hablan directamente de la nación, y asimismo se ha recurrido a las cartas privadas que permiten reconstruir la experiencia personal, y a fuentes hemerográficas. En cuanto a la estructuración, se ha realizado siguiendo los diversos compartimentos de la biografía del protagonista, que vivió entre 1883 y 1955, utilizándose como criterio la evolución de su filosofía, y dándose una especial atención a las etapas que discurren entre 1905 y 1932. Desde esta base, se han escrito nueve capítulos. El primero es la "Introducción y justificación", el segundo la "Metodología", 
el tercero el "Estado de la cuestión", y el noveno, las "Conclusiones". Los restantes, que componen el cuerpo de la investigación, son los siguientes: "La idea de nación en el joven Ortega (1883-1955)", “El patriotismo utópico de raíz neokantiana (1905-1912)", "El desarrollo del patriotismo fenomenológico: la idea de nación desde la Razón vital (1912-1922)", “La evolución del patriotismo fenomenológico: concreción teórica e intento de puesta en práctica (1922-1932)", y “Epílogo desde la Razón histórica: la idea de ultra-nación (1932-1955)".

3 En cada uno se ha aplicado el mismo método: el objetivo ha sido el de determinar la naturaleza del pensamiento orteguiano y ver cómo se proyecta en su análisis de la nación. Para ello, se ha tenido en cuenta el contexto ideológico y político, estudiándose tanto su influjo en el filósofo, como el de Ortega en su circunstancia. Cada etapa se ha finalizado con unas conclusiones, para facilitar después la comparación de todas ellas en las finales. De esta manera, el capítulo cuarto, "La idea de nación en el joven Ortega (1883-1905)", se ha centrado en aspectos que son fundamentales porque constituyen el sedimento sobre el que se irán depositando los aluviones de experiencias e ideas que configuran el conjunto. Para empezar, el Desastre del 98, que siempre le acompañará como punto de partida de su reflexión sobre el ser de España, como una preocupación que es tanto personal como generacional. También se estudia en este lugar su ambiente familiar, de carácter intelectual y liberal, y el influjo de dos personas: Francisco Navarro Ledesma y Ángel Ganivet. De ellos, y otros autores como Ramiro de Maeztu, Ernest Renan, Friedrich Nietzsche o Marcelin Berthelot, asumió una idea de nación basada en aspectos como la división de la nación entre masas y élites; y también la identificación del carácter español con el individualismo. Este capítulo concluye mostrando que Ortega plantea un patriotismo ambiguo, entre el casticismo y el vitalismo.

4 A continuación, en el espacio de tiempo tratado en el capítulo quinto, "El patriotismo utópico de raíz neokantiana (1905-1912)”, se analiza el gran cambio supuesto por el viaje de Ortega a Alemania, siguiendo las referencias de la moral de la ciencia. A nivel intelectual, el neokantismo le lleva a asumir una visión ética de la sociedad que se traduce en lo que se ha llamado, en base a su autocrítica postrera, "patriotismo utópico". Ortega defiende un ideal de nación perfecta ante el que debe de adaptarse la España real, mediante un Estado que imponga el socialismo ético. Mantiene así su elitismo de la etapa anterior, pero definido desde las ideas de Hermann Cohen o Paul Natorp. Alemania es también para el filósofo un referente de nación que le permite encontrar un modelo de socialismo nacionalizador que quiere exportar a España, y que verá encarnado en el movimiento populista de Alejandro Lerroux. Esta fase, si bien tiene ambigüedad terminológica (confundiéndose a veces las idas de nación, pueblo, nacionalismo...), es más precisa en tanto que Ortega se asemeja mucho más a la idea de Staatsnation.

5 Los capítulos seis y siete forman en realidad parte de una misma etapa, que se ha identificado con una forma de concebir la nación denominada "patriotismo fenomenológico". El primero, "El desarrollo del patriotismo fenomenológico: la idea de nación desde la Razón vital (1912-1922)", se centra en el nacimiento de esta actitud, y sus primeras manifestaciones prácticas. El segundo, "La evolución del patriotismo fenomenológico: concreción teórica e intento de puesta en práctica (1922-1932)", en su desarrollo a partir de la elaboración más precisa, y el intento de nacionalización de España más importante de todos en los que logró participar Ortega. Se estudia cómo 
asume una forma de analizar la nación que es consecuencia de su filosofía particular, la Razón vital, que hace de la circunstancia una clave básica. Frente a la imposición de utopías defenderá la reforma a partir de la realidad dada, lo que le lleva a buscar qué es lo concreto. Llegará a ver que, en el caso de la nación española, esto se encuentra en la región, y desarrollará un importante regionalismo que será fundamental durante todos estos años. En estos dos capítulos se estudian también acontecimientos clave como la Gran Guerra, los sucesos de verano de 1917 en España, la dictadura de Primo de Rivera, y la II República. Son experiencias de nación que sirven a Ortega para varias cosas: por un lado, esbozar una teoría del Estado basada en la organización social y la redención de las provincias, y por otro, ir percibiendo con pesimismo lo que llamará la rebelión del hombre-masa. En el capítulo sexto se estudia el surgimiento de estas ideas, y en el séptimo, su plasmación más concreta en tres libros fundamentales: España invertebrada (1922), La rebelión de las masas (1930), y La redención de las provincias y la decencia nacional (1931).

6 Por otro lado, en estos dos capítulos se analizan los instrumentos de nacionalización más ambiciosos de Ortega, la Liga de Educación Política de 1913, y la Agrupación al Servicio de la República de 1931. En relación con el segundo, se da una gran importancia al papel del filósofo en la II República, dado que es el escenario donde concluye su actuación política (aunque no pública, que volverá tras la Guerra civil), y se analiza con profundidad el debate constitucional en el que participó. También se trata en estos dos capítulos el influjo de personas como Miguel de Unamuno, Menéndez Pelayo, o Gumersindo de Azcárate, que le sirven para definir su idea de nación frente al casticismo y el nacionalcatolicismo los primeros, y en continuidad con el liberalismo el segundo. De todo ello se desprende una idea de nación con elementos de Kulturnation y de Staatsnation, pero donde priman mucho más los segundos.

7 El octavo capítulo, "Epílogo desde la Razón histórica: la idea de ultra-nación (1932-1955)", se centra en el Ortega que, desde su decepción con la II República en 1932, se retrae de la actividad pública, regresando a la misma después de la Guerra civil, pero desde un instrumento de nacionalización semi-público y no político como es el Instituto de Humanidades. Es una época de gran elaboración teórica, donde configura la Razón histórica, cuya principal consecuencia para la idea de nación es volver a equilibrar la teoría de la nación cívica y la nación cultural, debido al peso que da al pretérito. Este capítulo es más breve que los anteriores porque el objetivo de la tesis es estudiar la idea de nación de Ortega y su dimensión política. Ocurre que la teoría ya está prácticamente elaborada en 1932, con todos sus elementos clave (división entre masa y minoría selecta, defensa del proyecto colectivo frente al particularismo, regionalismo, y europeísmo). Desde entonces, su nueva sociología le llevará a cambiar algunos significantes, y el afianzamiento del europeísmo a elaborar la idea de ultra-nación. La Guerra civil, la dictadura de Francisco Franco, y la Guerra Fría, son las principales experiencias que influyen en el filósofo, llevándole a enfatizar su anticomunismo, y también su oposición al particularismo. En este Epílogo, se muestra que Ortega sigue analizando a España desde el patriotismo fenomenológico, esto es, partiendo de la base de que el elemento fundamental para comprender qué es la nación es partir de su realidad dada, que ahora identifica con la historia.

8 En cuanto a las conclusiones, responden a las preguntas que plantea la hipótesis. Para empezar, se demuestra que existen varias fases, en concreto cuatro: la del joven Ortega, la del filósofo neokantiano, la del que desarrolla la Razón vital, y, aunque también 
podemos considerarlo más una derivación de lo anterior que una nueva fase, la del Ortega de la Razón histórica. El cambio en la perspectiva intelectual es por tanto lo que justifica la existencia de varias etapas. Otra conclusión es la de que el pensamiento de Ortega incluye ingredientes de la teoría de la Staatsnation y de la Kulturnation, en cantidades que difieren según la etapa: en la fase neokantiana prima mucho más la primera y la fenomenológica prima, aunque por motivos distintos, la idea de nación cívica. En la fase juvenil y en la de la Razón histórica, la idea de nación cultural. Por tanto, se ha visto también que la idea de nación de Ortega no es contradictoria, sino coherente porque sigue una lógica: la evolución de su pensamiento. En este sentido, la última conclusión general es la de que la intención del filósofo a la hora de construir su idea de nación es la misma por la que comenzó a filosofar: para resolver su crisis existencial, dese la convicción de que España era la circunstancia que tenía que salvar para salvar también su yo. 